\title{
EDUCAÇÃO NÃO FORMAL EM ASTRONOMIA: ANÁLISE DE ARTIGOS ACADÊMICOS NACIONAIS E INTERNACIONAIS
}

\section{NON-FORMAL EDUCATION IN ASTRONOMY: ANALYSIS OF NATIONAL AND INTERNATIONAL ACADEMIC ARTICLES}

Leandro Donizete Moraes ${ }^{1}$

ORCID iD: 0000-0002-1058-1123

Ismar Frango Silveira ${ }^{2}$

ORCID iD: 0000-0001-8029-072X

\begin{abstract}
RESUMO
Neste trabalho são analisados artigos sobre a educação não formal em Astronomia, publicados entre 2009 e 2019, em revistas acadêmicas nacionais e internacionais. Nesta pesquisa, do tipo Estado da Arte, utilizou-se a análise de conteúdo de Laurence Bardin. Foram identificados 225 artigos científicos a partir de um levantamento no Portal de Periódicos da Coordenação de Aperfeiçoamento de Pessoal de Nível Superior (CAPES). As categorias de análise foram: ano de publicação, país de origem dos artigos, instituição, revista, conteúdos e foco temático. Foi observado que a educação não formal pode ser abordada de várias maneiras e em diversos locais, ampliando a oferta de atividades, ações e projetos sobre Astronomia que envolvem pessoas com diferentes níveis de escolaridade. Os artigos apresentaram como tendências o crescente uso da tecnologia, atividades em espaços não formais e a aproximação entre a educação formal e não formal. Porém, foram detectados vários problemas, como a pequena quantidade de pesquisas sobre Astronomia Amadora, Astronomia Indígena, história da Astronomia, relações da Astronomia com o meio ambiente, inclusão e igualdade de gênero. Embora a produção internacional seja diversificada e presente em muitos países, os Estados Unidos possuem grande parte dos artigos, instituições e revistas, enquanto outros países têm pouca produção acadêmica. Do mesmo modo, foi identificada uma concentração de artigos brasileiros nas regiões Sudeste e Sul e a ausência de artigos na região Norte.
\end{abstract}

Palavras-chave: Educação em Astronomia. Educação não Formal. Estado da Arte.

\section{ABSTRACT/ RESUMEN}

This work analyzes articles on non-formal education in Astronomy, published between 2009 and 2019, in national and international academic journals. In this state-of-the-art research, Laurence Bardin's content analysis was used. 225 scientific articles were identified from a survey on the Portal of Journals of the Coordination for the Improvement of Higher Education Personnel (CAPES). The categories of analysis were: year of publication, country of origin of the articles, institution, magazine, contents and thematic focus. It was observed that non-formal education can be approached in several ways and in different places, expanding the offer of activities, actions and projects on Astronomy that involve people with different levels of education. The articles presented as trends the increasing use of technology, activities in non-formal spaces and the approximation between formal and non-formal education.

\footnotetext{
${ }^{1}$ Doutorando em Ensino de Ciências e Matemática pela Universidade Cruzeiro do Sul (UNICSUL). Professor de Educação Básica da Secretaria Estadual de Educação de Minas Gerais (SEE-MG), São Tomás de Aquino, Minas Gerais, Brasil. Endereço para correspondência: Rua Orlando Soares Vilas Boas, 37, Jardim dos Ipês, São Tomás de Aquino, Minas Gerais, Brasil, CEP: 37.960-000. E-mail: leandrosta2009@ hotmail.com.

2 Doutor em Engenharia Elétrica pela Universidade Federal de Juiz de Fora (UFJF). Professor Adjunto da Universidade Presbiteriana Mackenzie, Professor Titular da Universidade Cruzeiro do Sul (UNICSUL), São Paulo, São Paulo, Brasil. Endereço para correspondência: Rua Galvão Bueno, 868, Liberdade, São Paulo, Brasil, CEP: 1506-000. E-mail: ismar.silveira@ cruzeirodosul.edu.br.
} 
However, several problems were detected, such as the small amount of research on Amateur Astronomy, Indigenous Astronomy, Astronomy history, Astronomy's relations with the environment, inclusion and gender equality. Although international production is diverse and present in many countries, the United States has most articles, institutions and magazines, while other countries lave little academic production. Likewise, a concentration of Brazilian articles was identified in the Southeast and South regions and the absence of articles in the North region.

Keywords/Palabras clave: Astronomy Education. Non-formal Education. State of Art.

\section{INTRODUÇÃO}

Embora a Astronomia desperte a curiosidade pelo céu, muitas pessoas se afastam dessa ciência pelas dificuldades enfrentadas em seu estudo. Até mesmo nas instituições oficiais de ensino, o aprendizado de Astronomia nem sempre resulta em conhecimentos necessários para a compreensão dos conceitos e fenômenos astronômicos, podendo resultar no desinteresse dos estudantes por esta ciência, que tanto contribui para o entendimento do nosso lugar no Cosmos. Do mesmo modo, os aspectos míticos, holísticos e ritualísticos da Astronomia nem sempre são valorizados em seu ensino, fazendo com que os estudantes não conheçam os aspectos sociais e antropológicos dessa ciência.

Sobre os problemas enfrentados no ensino de Astronomia, Langui e Nardi (2012), por exemplo, analisaram a existência de diversas concepções alternativas de alunos e professores e ausência de atividades em espaços não formais para este ensino, mostrando que são necessárias ações para que as pessoas compreendam os conceitos e fenômenos estudados por esta ciência. No nível de pós-graduação, Menezes e Batista (2020) investigaram concepções equivocadas de mestrandos sobre o Sistema Solar e refletiram sobre os desafios da formação de professores para o ensino de Astronomia.

Logo, para solucionar estes e demais problemas, é preciso investigar a maneira pela qual esta ciência é ensinada. Porém, a educação em Astronomia possui uma história recente. Langhi e Nardi (2012) explicam que, em 1922, foi criada a União Astronômica Internacional, International Astronomical Union (IAU), e só em 1970 foi iniciado um movimento de incentivo à educação em Astronomia através do Astronomy Education Material, que consiste em materiais de apoio ao professor para o ensino de Astronomia. No Brasil, os primeiros trabalhos foram divulgados entre 1985 e 1988 e o primeiro encontro internacional sobre educação em Astronomia ocorreu em 1988, nos Estados Unidos. Além disso, a construção dos primeiros observatórios, trouxe oportunidades para o aprendizado de Astronomia para o público, em geral, e demais atividades foram sendo realizadas tanto nas escolas quanto em outros ambientes. 
A partir dos problemas enfrentados pela educação em Astronomia e, em especial, da educação não formal em Astronomia, o presente artigo busca identificar e analisar a produção acadêmica nacional e internacional sobre esta temática. A presente análise se torna importante, pois apresenta tendências, problemas e possíveis soluções, por meio de vários artigos analisados e suas respectivas pesquisas.

Como diferencial deste trabalho, encontra-se o Estado da Arte de artigos científicos publicados em revistas acadêmicas nacionais e internacionais sobre educação não formal em Astronomia, visto que são raros os mapeamentos sobre esta temática. Esta conclusão está fundamentada em nossa análise dos artigos presentes no Portal de Periódicos da CAPES, apresentada neste artigo, e também em pesquisas no Google Acadêmico em 15 de junho de 2020, nas quais não foram encontrados trabalhos específicos sobre o Estado da Arte de artigos em revistas nacionais e internacionais sobre educação não formal em Astronomia. Sendo assim, entendeu-se que este trabalho contribui para a área de ensino de Ciências, pois tem como objetivo identificar tendências e problemas relacionados à educação não formal em Astronomia no nível nacional e internacional, a fim de refletir sobre possíveis soluções. Quanto à escolha pela análise de artigos científicos se deve ao fato de que os artigos são uma maneira pela qual a comunidade acadêmica divulga suas pesquisas, apresentando resultados referentes às especificidades de determinada área.

Esta pesquisa do tipo Estado da Arte, foi realizada uma pesquisa do tipo estado da arte. André (2001) explica que o Estado da Arte consiste na revisão e análise, de forma crítica, da produção de determinada área, buscando aprimoramentos. À vista disso, para organizar, explorar o material e tratar os resultados, foi utilizada a análise de conteúdo de Bardin (2006). As contribuições de demais autores, por meio de suas pesquisas sobre o Estado da Arte, também foram importantes ao nortear os procedimentos adotados neste artigo. Ademais, dentre os autores, Bussi e Bretones (2013) mapearam a produção sobre educação em Astronomia nos trabalhos dos Encontros Nacionais de Pesquisa em Educação em Ciências (ENPEC); Santos, Lucas, Sanzovo e Pimentel (2019) analisaram o uso da tecnologia digital em pesquisas sobre o ensino de Astronomia e Bueno, Oliveira, Nogueira e Rodrigues (2019) investigaram pesquisas que apresentam saberes sobre o céu produzidos por culturas indígenas no Brasil.

\section{REFERÊNCIAL TEÓRICO}

A educação que ocorre nas instituições de ensino, de forma organizada e estruturada, é chamada de educação formal. Para Langhi e Nardi (2012), na educação formal existem 
avaliações e cronogramas específicos e a educação não formal tem o caráter coletivo, com liberdade de escolha de métodos e conteúdos. De acordo com Marques (2017), a educação não formal também é organizada, porém possui maior flexibilidade em relação ao tempo e locais de aprendizado. Os planetários, observatórios, centros e museus de Ciências são exemplos de locais onde ocorre a educação não formal. Noy, James e Bedler (2016) explicam que a educação informal é aquela que acontece durante a vida, no trabalho e em conversas com amigos, por exemplo. As leituras de livros de Astronomia, notícias na mídia e conversas ocasionais sobre esta ciência também fazem parte da educação informal. Marques e Freitas (2017) analisam que os termos empregados para a educação não formal são mal definidos, assim como as diferentes tipologias educacionais. Devido a estas indefinições, neste artigo são adotadas as definições apresentadas neste parágrafo sobre cada tipo de educação.

Muitas pesquisas são feitas em busca de soluções para os problemas enfrentados na educação em Astronomia. Na educação formal, por exemplo, Amaral e Oliveira (2011) analisaram erros conceituais sobre Astronomia em livros didáticos; Langhi (2011) criou um catálogo de concepções alternativas, identificando erros tanto de alunos quanto de professores, reforçando a necessidade de um esforço nacional para que as pessoas aprendam corretamente os fenômenos astronômicos; Beliz (2016) apresentou um jogo didático digital sobre Astronomia e constatou concepções de alunos sobre conceitos astronômicos; e Barbosa e Voelzke (2016) identificaram o baixo nível de aprendizado de alunos sobre conceitos de Astronomia. Estas e demais pesquisas refletem as necessidades encontradas na educação formal em Astronomia.

Também existem problemas na educação não formal em Astronomia. Marques (2017) apresentou a análise de divulgadores e especialistas nesta área e constatou a ausência de uma entidade coordenadora nacional, para que ações sejam realizadas em todas as regiões do país e não somente no Sudeste e Sul do Brasil; Yano (2017) analisou a importância dos planetários para a formação de professores e apresentou vários problemas relacionados ao distanciamento entre as escolas e os espaços não formais e Borges (2017) elaborou uma sequência didática, após a visita de seus alunos a um planetário móvel e observou que são necessárias mais pesquisas e atividades práticas sobre educação não formal em Astronomia.

O uso de outros locais de aprendizado, como os observatórios, planetários, museus e centros de Ciências, pode fazer com que o público geral compreenda conceitos importantes da ciência que estuda o céu. Além disso, as instituições de ensino também podem se beneficiar destes ambientes, através de visitas escolares, atividades diversificadas de observação do céu, formação continuada de professores e outros meios para que os alunos e professores se encantem pela Astronomia e aprendam as verdadeiras causas dos fenômenos astronômicos. 
Embora sejam apresentados diversos problemas, existem várias pesquisas e incentivos à educação não formal em Astronomia no Brasil e no mundo. A União Astronômica Internacional, International Astronomical Union (IAU), por exemplo, incentiva o ensino de Astronomia em vários locais. Dentre suas ações, destacam-se diversos projetos de divulgação e ensino de Astronomia, como o Ano Internacional da Astronomia, em 2009, que contou com inúmeras atividades em vários países. No nível nacional, os eventos científicos promovem a divulgação e debate sobre pesquisas e relatos de experiências de professores em muitas regiões.

Os astrônomos amadores auxiliam no ensino de Astronomia divulgando eesta ciência e contribuições com os astrônomos profissionais. Para mais, atividades de extensão universitária também aproximam a Astronomia do público e o uso de espaços não formais, como os observatórios, planetários, centros de Ciências e até mesmo de ambientes virtuais, permite às pessoas o aprendizado de Astronomia, mesmo que não frequentem o sistema formal de ensino.

\section{METODOLOGIA}

A presente pesquisa, do tipo Estado da Arte, tem abordagem qualitativa e usa a análise de conteúdo de Bardin (2006) para identificar e analisar as tendências e problemas da educação não formal em Astronomia no Brasil e no mundo. Para Megid Neto (2009), o Estado da Arte tem por objetivo o conhecimento de características e tendências de um campo de conhecimento por meio da produção acadêmica relacionada a ele. Quanto á pesquisa qualitativa, à luz de Esteban (2010), a pesquisa qualitativa consiste em uma atividade de sistematização que busca compreender a profundidade de fenômenos educativos e sociais. A pesquisa qualitativa também investiga a transformação de práticas e cenários socioeducativos, além da tomada de decisões e o desenvolvimento de um corpo organizado de conhecimentos. Já a análise de conteúdo de Bardin (2006), tem por objetivo explicitar, sistematizar e expressar o conteúdo de mensagens através de três fases: pré-análise; exploração do material e tratamento dos resultados, inferência e interpretação.

A pré-análise é uma fase de organização, através da escolha dos documentos, formulação de hipóteses e objetivos e de elaboração de indicadores para que seja feita a fundamentação da interpretação final. Nesta fase, realizou-se a escolha dos documentos, na seleção dos materiais; leitura flutuante, em contato inicial com os documentos; formulação de hipóteses e objetivos, através de afirmações iniciais e referenciação dos índices e elaboração de indicadores, por temas que se repetem, por exemplo.

Os critérios de seleção de conteúdos de Bardin (2006) são: a exaustividade, para que 
seja esgotada a totalidade da comunicação; representatividade, porque devem existir informações que representam o universo a ser pesquisado; e homogeneidade, pois os dados devem se referir à pertinência e ao tema abordado, para que os documentos sejam condizentes com os objetivos propostos na pesquisa.

Na segunda fase de análise, Bardin (2006) explica que a exploração do material deve ser realizada codificando o material, definindo categorias de análise e identificando as unidades de registro e de contexto. A autora também ressalta o critério da exclusividade, para a categorização dos elementos em apenas um parâmetro de análise. Por fim, na última fase é feito o tratamento dos resultados, inferência e interpretação.

Inicialmente foi realizado o levantamento bibliográfico no Portal de Periódicos da CAPES em busca de artigos relacionados com a educação não formal em Astronomia. Seguindo os passos da análise de conteúdo de Bardin (2006), foi realizada a pré-análise por meio da leitura flutuante dos títulos, resumos, demais informações disponíveis nas revistas e, em alguns casos, do texto completo dos artigos. Depois foram selecionados 225 artigos que satisfaziam os critérios da pesquisa. Na sequência, foi formulada como hipótese inicial, que as pesquisas em educação não formal em Astronomia já são realizadas em vários países e apresentam metodologias diversificadas. Porém, muitas regiões carecem de pesquisas nesta área e determinados temas não são abordados de maneira satisfatória.

Ainda na segunda fase, exploração do material, foram investigadas as categorias de análise: ano de publicação, país de origem, instituição, revista, conteúdos e foco temático. $\mathrm{O}$ ano de publicação foi obtido por meio de resumos e informações dos artigos nas páginas das revistas na internet. Os dados sobre as categorias país de origem e instituição foram identificados por meio do resumo, informações da revista ou do texto completo do artigo. A saber, em várias revistas, estes dados não estavam disponíveis em suas páginas, sendo necessária a análise dos textos completos dos artigos. Na categoria revista também foi identificado o país de cada revista. Algumas revistas foram classificadas como parcerias internacionais, por não serem produzidas em um país específico. A categoria conteúdos analisa os conteúdos relacionados à Astronomia presentes nos artigos, e, em conclusão, a categoria foco temático identifica os focos e subfocos temáticos dos artigos por meio de relatos de atividades, descrição de projetos e demais informações identificadas. Por fim, na última fase da análise de conteúdo, inferência e interpretação, foram construídos gráficos e tabelas a partir das categorias de análise para subsidiar a interpretação dos resultados.

Muitos autores apresentam diferentes visões e tipologias sobre as definições de educação formal, não formal e informal. Porém, neste artigo são adotadas as definições sobre 
estes termos de Langhi e Nardi (2012), Marques (2017) e Noy, James e Bedley (2016). Sendo assim, foram selecionados os artigos que possuem pesquisas nas quais a Astronomia foi abordada com aspectos da educação não formal, como a flexibilidade de tempo e locais de aprendizado. Além disso, os limites entre os tipos de educação foram analisados em busca de artigos que possam contribuir para a educação não formal em Astronomia.

Como muitos autores não diferenciam a educação não formal da educação informal, iniciou-se a pesquisa no Portal de Periódicos da CAPES utilizando-se da combinação dos descritores "Astronomia" com "não formal" e "informal". Esta combinação também foi feita em inglês com "Astronomy", "non formal" e "informal". O período analisado foi de 2009 a 2019 e foram pesquisados somente artigos em periódicos revisados por pares. Já a coleta de dados foi realizada entre os meses de fevereiro e março de 2020.

Ao realizar a pesquisa no Portal de Periódicos da CAPES, foram apresentados vários resultados, porém analisou-se cada artigo através de seu título, resumo e palavras-chave. Como critérios de exclusão, analisou-se a ausência dos descritores nos títulos, resumos ou palavraschave. Além disso, foram excluidos os artigos que apresentaram os descritores analisados, porém não apresentavam pesquisas relacionadas especificamente com a educação não formal em Astronomia. Nesta pré-análise, identificou-se 225 artigos que possuem pesquisas relacionadas à educação não formal em Astronomia.

\section{ANÁLISES E RESULTADOS}

Após identificar os 225 artigos relacionados com a educação não formal em Astronomia, realizou-se análises sobre o ano de publicação, país de origem dos artigos, instituições, revista, conteúdos e focos temáticos.

\subsection{Ano de publicação}

Ao analisar o ano de publicação de uma amostra de produções acadêmicas, é possível identificar alterações na quantidade de artigos publicados no decorrer dos anos e realizar inferências sobre estas mudanças. Sendo assim, na Figura 1 é apresentada a quantidade de artigos específicos de educação não formal em Astronomia e o ano de publicação. 


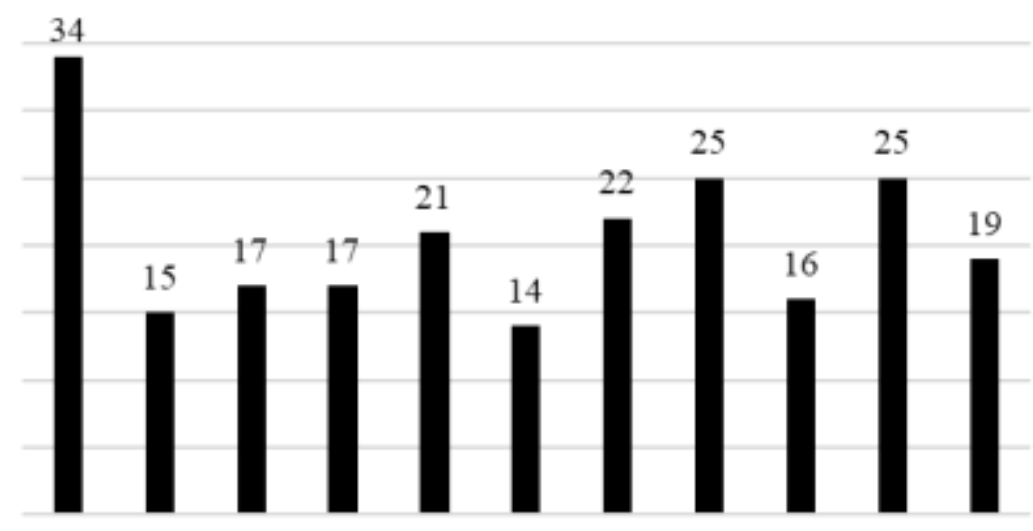

20092010201120122013201420152016201720182019

Figura 1 - Ano de publicação dos artigos sobre educação não formal em Astronomia Fonte: Elaborada pelos autores.

Na Figura 1, observa-se que o ano de 2009 apresentou mais artigos do que os demais anos. Dentre as justificativas para esta diferença, estão as comemorações do Ano Internacional da Astronomia, em 2009. Vários artigos científicos foram publicados neste período, apresentando relatos sobre atividades realizadas em eventos relacionados a estas comemorações. E mesmo com o incentivo ao ensino de Astronomia, proporcionado pelo Ano Internacional da Astronomia, percebe-se que a quantidade de publicações nos demais anos não aumentou significativamente, porém diminuiu em relação ao ano de 2009.

Em 2014 houve a menor publicação de artigos e as publicações aumentaram e diminuíram ao longo dos anos. A média aritmética simples da quantidade de artigos foi de 20 artigos por ano. A Figura 1 demonstra que a produção anual de artigos, identificados neste levantamento bibliográfico, não apresentou sinais de aumentos significativos. Mesmo com diversos incentivos para o aumento das produções científicas, como os eventos científicos, comemorações, como o Ano Internacional da Astronomia, e demais atividades, os dados indicam que são necessários maiores incentivos para que mais pesquisas sejam realizadas.

\subsection{País de origem dos artigos}

Ao realizar a pesquisa no Portal de Periódicos da CAPES, foram encontrados artigos de diversos países. A análise das produções e, dos respectivos países, é importante para a obtenção de parâmetros relacionados à evolução das pesquisas sobre educação não formal em Astronomia a nível mundial. A Figura 2 apresenta a quantidade de artigos por país. 


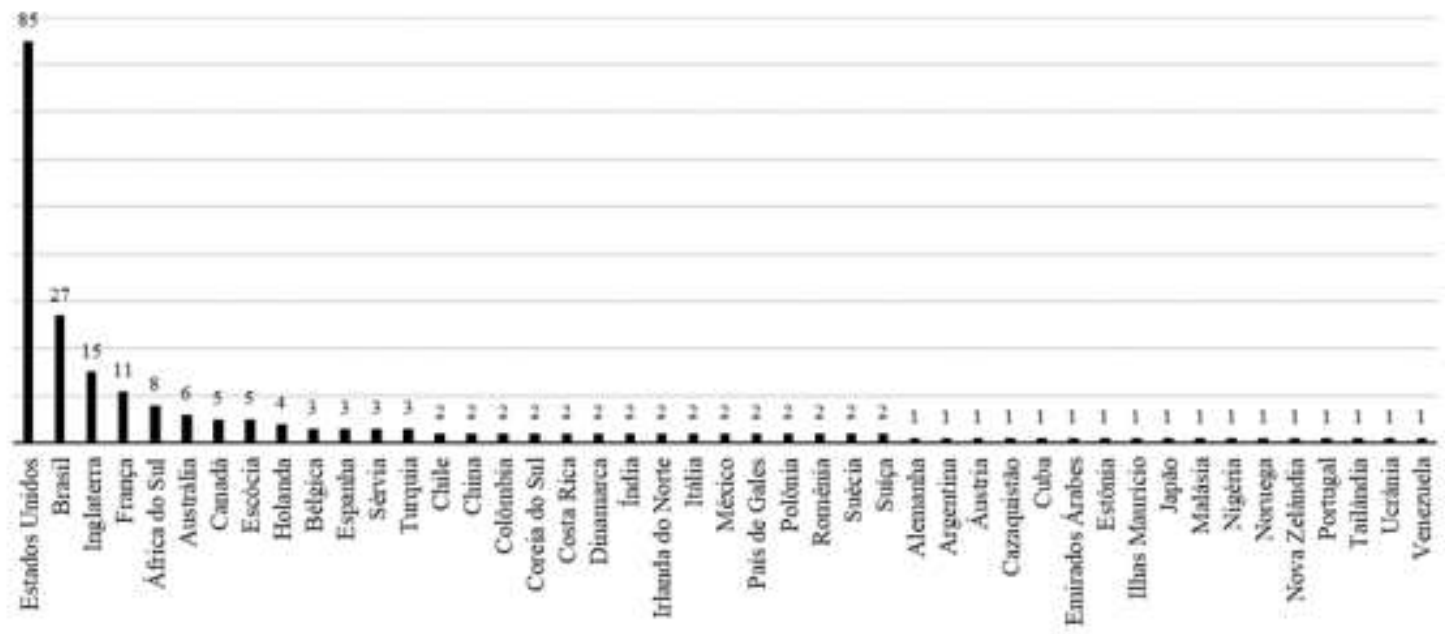

Figura 2 - País de origem dos artigos Fonte: Elaborada pelos autores.

Ao analisar a Figura 2, é observado que 45 países apresentaram artigos nesta pesquisa. Dos 225 artigos, os Estados Unidos foram representados em 85 (37,8\% do total), o Brasil apresentou 27 artigos (12\% do total), a Inglaterra 15 artigos (6,7\% do total), a França 11 artigos (4,9\% do total) e os demais países apresentaram quantidades menores de artigos. A África do Sul apresentou 8 artigos, seguida da Austrália com 6 artigos e do Canadá e Escócia com 5 artigos cada. Na sequência, a Holanda foi representada por 4 artigos e quatro países apresentaram 3 artigos cada. Quinze países apresentaram 2 artigos e dezessete países apresentaram 1 artigo cada.

É importante destacar que 18 artigos brasileiros foram obtidos através da combinação entre os descritores "Astronomia", "não formal" e "informal", e que os outros 9 artigos foram obtidos na combinação entre os descritores em língua inglesa: "Astronomy", "non formal” e “informal”. Além disso, a pesquisa com descritores em língua portuguesa resultou em 11 artigos estrangeiros. Estes dados mostram a importância de pesquisas com descritores em língua portuguesa e inglesa, para que sejam identificados artigos tanto nacionais quanto internacionais, que podem enriquecer a amostra a partir das pesquisas apresentadas.

A Figura 2 também demonstra que pesquisas sobre a educação não formal em Astronomia são desenvolvidas por diversos países diferentes. Como a educação não formal pode ser realizada em diferentes ambientes, a obtenção destes dados é importante para que possa ser investigado o panorama global sobre as diversas maneiras pelas quais a Astronomia é ensinada, de maneira não formal, em diferentes culturas e visões sobre a educação. A seguir, na Figura 3 é apresentada a distribuição de artigos brasileiros por região. 


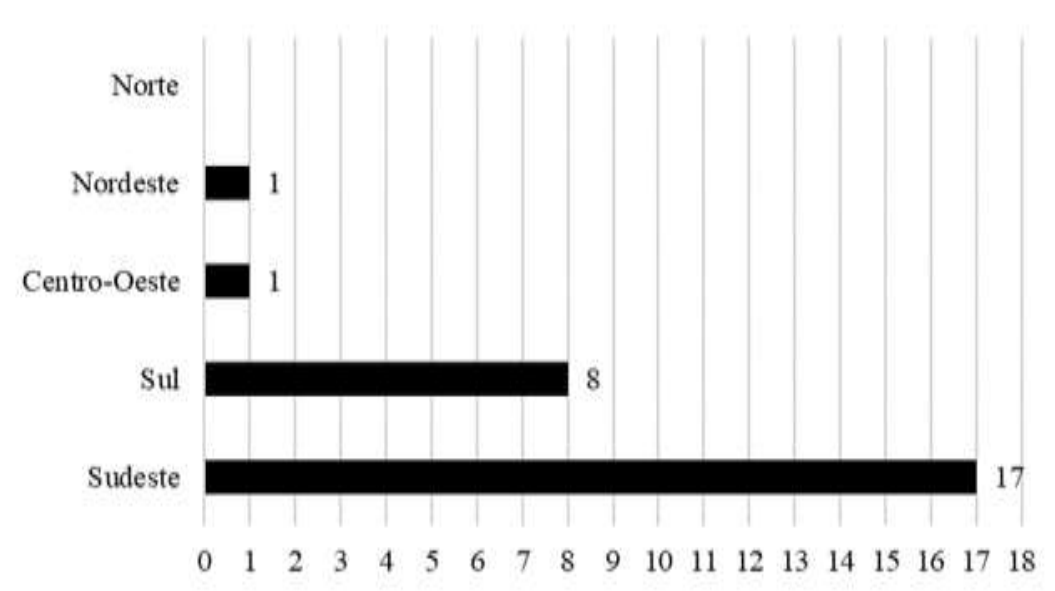

Figura 3 - Quantidade de artigos brasileiros por região do Brasil Fonte: Elaborada pelos autores.

Conforme apresentado na Figura 3, a região Sudeste possui 17 artigos (63\% dos artigos brasileiros), a região Sul 8 artigos (29,6\% dos artigos brasileiros) e as regiões Centro-Oeste e Nordeste apresentaram um artigo cada. A região Norte não foi representada por nenhum artigo. Estes dados mostram que é preciso o incentivo ao ensino de Astronomia nos vários tipos de educação. Do mesmo modo, uma melhor distribuição das instituições de ensino e dos espaços não formais é necessária. Para Marques (2017), esta distribuição é desequilibrada e é insuficiente a quantidade de espaços não formais e instituições que promovem a educação não formal em Astronomia no país.

Embora existam problemas relacionados à distribuição heterogênea das atividades e pesquisas sobre educação não formal em Astronomia no Brasil, várias ações são realizadas. Dentre elas, tem-se as atividades e comemorações do Ano Internacional da Astronomia, em 2009, as quais ocorreram em todas as regiões do Brasil; a Olimpíada Brasileira de Astronomia e Astronáutica (OBA), a qual incentiva alunos e professores de todo o país a estes estudos; eventos científicos nacionais que contribuem para o incentivo ao ensino de Astronomia como, por exemplo, o Simpósio Nacional de Ensino de Física (SNEF), que apresenta trabalhos sobre educação não formal em Astronomia e já foi realizado em todas as regiões do país; a divulgação de pesquisas pela internet, que também tem expandido a educação não formal em Astronomia, dentre outras ações.

Os dados da categoria país de origem dos artigos refletem o interesse de pesquisadores de diversos países sobre esta ciência. Porém, existem vários problemas a serem solucionados para o desenvolvimento efetivo da educação não formal em Astronomia nos diversos países e suas regiões. Dentre os problemas, foi observada a pequena quantidade de artigos em alguns 
países, como demonstra a Figura 2, e distribuição desigual desta produção em regiões dos países, como ocorre no Brasil, conforme identificado na Figura 3. Ao serem relacionadas as Figuras 1, 2 e 3, observa-se que a produção mundial apresentada nesta amostra não aumentou significativamente durante os anos. Porém, esta distribuição contém pesquisas de diversos países e ações locais devem ser realizadas para que os indivíduos, das diferentes regiões de cada país, aprendam Astronomia através de diversas abordagens.

\subsection{Instituições de origem dos artigos}

Após analisar o ano de publicação dos artigos e o país de origem, identificou-se também as instituições de cada artigo. Os dados referentes às instituições de origem são importantes para a identificação de projetos em desenvolvimento por estas instituições, atividades desenvolvidas com o público, aproximação da educação formal e não formal, dentre outros benefícios da pesquisa nesta área. De início, foi analisada a relação entre a quantidade de artigos e as instituições de cada país, conforme apresentado na Tabela 1.

Tabela 1 - Relação entre a quantidade de artigos e as instituições de origem

\begin{tabular}{|c|c|c|}
\hline País & Artigos & Instituições \\
\hline Estados Unidos & 85 & 60 \\
\hline Brasil & 27 & 20 \\
\hline Inglaterra & 15 & 12 \\
\hline França & 11 & 10 \\
\hline África do Sul & 8 & 5 \\
\hline Austrália & 6 & 5 \\
\hline Canadá & 5 & 4 \\
\hline Escócia & 5 & 3 \\
\hline Holanda & 4 & 3 \\
\hline Espanha e Turquia & 3 & 3 \\
\hline Bélgica e Sérvia & 3 & 2 \\
\hline $\begin{array}{l}\text { Chile, China, Colômbia, Coréia do Sul, Dinamarca, Índia, } \\
\text { Polônia, Suécia, Suíça }\end{array}$ & 2 & 2 \\
\hline $\begin{array}{c}\text { Costa Rica, Irlanda do Norte, Itália, México, País de Gales, } \\
\text { Romênia }\end{array}$ & 2 & 1 \\
\hline $\begin{array}{c}\text { Alemanha, Argentina, Áustria, Cazaquistão, Cuba, Emirados } \\
\text { Árabes, Estônia, Ilhas Maurício, Japão, Malásia, Nigéria, } \\
\text { Noruega, Nova Zelândia, Portugal, Tailândia, Ucrânia e } \\
\text { Venezuela }\end{array}$ & 1 & 1 \\
\hline Total & 225 & 173 \\
\hline
\end{tabular}

Fonte: Elaborada pelos autores.

Na Tabela 1 é possível observar que nesta amostra existe uma grande quantidade de instituições nas quais os artigos científicos foram produzidos. Este fato revela a diversidade de 
instituições e, consequentemente, de autores dos artigos. Os dados da Tabela 2 são importantes por mostrarem que existem muitas pesquisas sobre educação não formal em Astronomia sendo desenvolvidas no mundo, porém também é possível observar que muitos países foram representados por uma pequena quantidade de pesquisas, mostrando que é preciso que mais pesquisas sejam realizadas sobre esta temática nestes países.

Das 173 instituições, 138 são universidades, 8 observatórios astronômicos, 7 centros de pesquisa e 7 são institutos de pesquisa. Também fazem parte a IAU; União das Nações Unidas para a Educação, a Ciência e a Cultura (UNESCO); Sociedade Astronômica da África do Sul; Sociedade Astronômica Americana; Sociedade Astronômica da França; Adler Planetarium, dos Estados Unidos; Associação Astronômica Britânica; Greanpeace; Academia de Ciências da Índia; Organização Europeia de Pesquisa Astronômica (ESO); e do Brasil, a Fundação Oswaldo Cruz (FIOCRUZ), Museu de Astronomia e Ciências Afins (MAST), e Laboratório Nacional de Astrofísica (LNA).

As instituições que apresentaram mais artigos foram a Universidade da Califórnia, nos Estados Unidos, com 8 artigos; o MAST, no Brasil, e as universidades Johns Hopkins e Cambridge, nos Estados Unidos, com 4 artigos cada. Na sequência, 5 instituições apresentaram 3 artigos cada; 26 participaram com 2 artigos e 138 instituições produziram 1 artigo. A presença de grandes instituições internacionais, como a NASA, UNESCO, ESO, universidades, institutos, observatórios, centros de pesquisa, associações e demais instituições, demonstra a importância da pesquisa em educação não formal em Astronomia, devido à relevância das instituições em que foram produzidas.

\subsection{Revistas cientificas}

No levantamento bibliográfico realizado no Portal de Periódicos da CAPES, foram selecionadas somente revistas acadêmicas revisadas por pares. Os 225 artigos pertencem a 129 revistas científicas. Em relação à quantidade de artigos publicados, Proceedings of the International Astronomical Union, dos Estados Unidos, publicou 29 artigos e as demais revistas publicaram quantidades menores, sendo que uma revista publicou 9 artigos; outra revista publicou 7 artigos; duas publicaram 6 artigos; duas publicaram 5 artigos; três publicaram 4 artigos e seis publicaram 3 artigos. Quinze revistas publicaram 2 artigos cada e noventa e oito publicaram 1 artigo cada.

Os Estados Unidos possuem 39 revistas nesta amostra, o que corresponde a 30\% do total. 28 revistas pertencem a parcerias internacionais e 18 revistas são originárias da Holanda. 
O Brasil foi representado por 12 revistas, seguido da Suíça, com 6 revistas, e da África do Sul com 5. Três países apresentaram 3 revistas cada, três países foram representados por 2 revistas e seis países tiveram 1 revista nesta amostra. Em relação às revistas brasileiras, o Caderno Brasileiro de Ensino de Física publicou 4 artigos e a Revista Brasileira de Ensino de Física publicou 2 artigos, conquanto que as demais revistas publicaram 1 artigo cada.

Estas revistas científicas contribuem para a divulgação de pesquisas acadêmicas em várias partes do planeta. As revistas criadas através de parcerias internacionais, por exemplo, representam um aspecto importante da sociedade acadêmica da atualidade, haja vista o conhecimento e a informação serem disponíveis a nível mundial, contribuindo para o crescimento em conjunto da educação e da pesquisa. Porém, a distribuição desigual das pesquisas científicas por meio dos artigos, conforme verificado na análise dos países, das instituições e das revistas, demonstra que é preciso maior investimento em pesquisa e educação em países em todo o globo, em especial, naqueles que carecem de um sistema de ensino e rede de educação não formal.

\subsection{Conteúdos dos artigos analisados}

Ao analisar os resumos e textos completos dos artigos, é possível identificar os conteúdos abordados em cada pesquisa. Para esta identificação, foi criada uma nuvem de palavras, através da ferramenta WordArt (http://www.wordart.com). A nuvem de palavras é mostrada na Figura 4. Quanto maior a palavra, mais artigos estudaram o respectivo conteúdo.

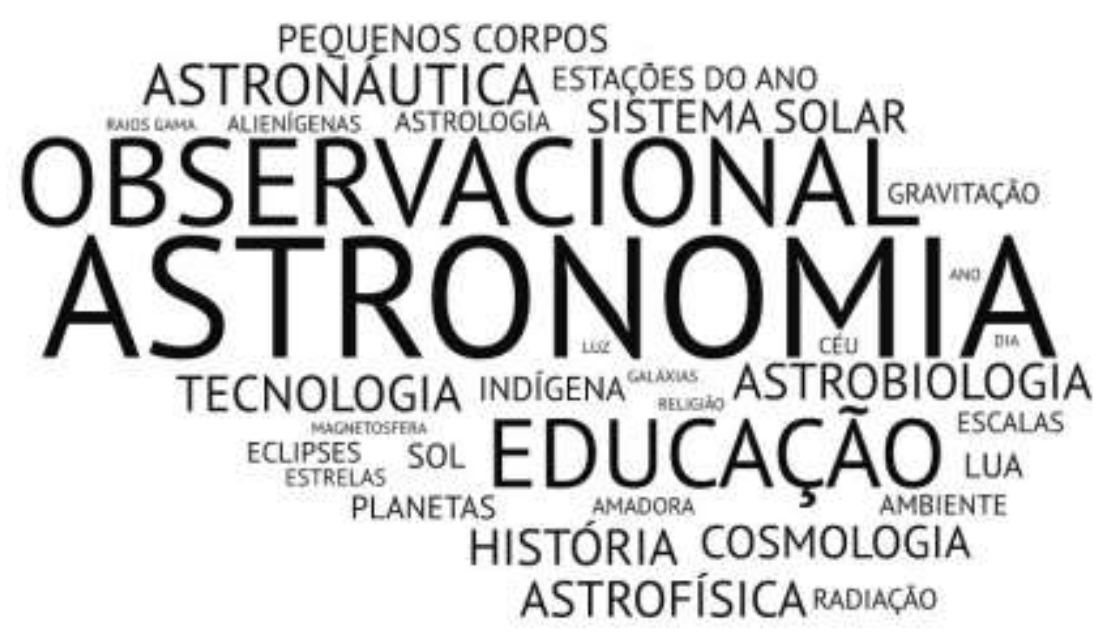

Figura 4 - Nuvem de palavras sobre os conteúdos presentes nos artigos analisados Fonte: Elaborada pelos autores.

Como observado na nuvem de palavras da Figura 4, o conteúdo Astronomia, em geral, 
foi apresentado em uma grande quantidade de artigos. 62 artigos explicaram sobre a Astronomia, em geral, através de resultados de pesquisas; interdisciplinaridade com outras áreas; explicações sobre laboratórios, observatórios e outros ambientes de estudo; divulgação desta ciência; entre outras abordagens. Na sequência, a Astronomia Observacional esteve presente em 38 artigos, por meio de atividades de observação em espaços não formais; tendo apresentação de projetos e relatos de concepções do público destes locais. 25 artigos estão representados na Figura 4 através da palavra Educação, pois abordam a aproximação entre a educação formal e não formal, por meio de atividades desenvolvidas com alunos em espaços não formais e outras atividades, como a Olimpíada Brasileira de Astronomia e Astronáutica, por exemplo. Também pertencem ao conteúdo Educação, os relatos sobre a inserção da Astronomia em sistemas de ensino, tendo a influência desta ciência na educação, em geral, e pesquisas sobre a formação de professores, em diferentes ambientes e metodologias.

A Astronáutica esteve presente em 8 artigos, descrevendo a exploração do espaço por missões e programas espaciais. A História, no caso da Astronomia, foi discutida em 6 artigos, através de relatos sobre mitos, história de observatórios e demais instituições, bibliografias de astrônomos e a evolução da Astronomia. A Tecnologia foi abordada em 6 artigos, por meio de relatos sobre descobertas utilizando telescópios modernos, computação quântica, interpretação de imagens, análise espectral e demais usos da tecnologia para a pesquisa e ensino de Astronomia; 6 artigos estudaram a Astrofísica, mostrando resultados de pesquisas e aproximações da Astronomia com a Física; 6 artigos investigaram pesquisas sobre a Astrobiologia, por meio de relatos sobre um Curso Online Aberto e Massivo (MOOC), descrição de pesquisas nesta área e busca por vida em outros planetas; 5 artigos estudaram o Sistema Solar e suas principais características. A Cosmologia foi abordada em 5 artigos, que contaram com estudos sobre Buracos Negros, Big Bang e a origem, evolução e destino do Universo. Finalmente, 5 artigos estudaram os pequenos corpos, como os cometas e meteoritos. Os demais conteúdos foram apresentados em menor quantidade.

O estudo dos conteúdos é importante por identificar tendências na abordagem de determinados conteúdos e problemas enfrentados por outros. Observa-se, na nuvem de palavras, que estudos sobre Astronomia, em geral, a observação astronômica e a aproximação entre educação formal e não formal, se destacam nas pesquisas. Além disso, muitas pessoas se interessam pela Astronomia Moderna, e isto reflete na abordagem de conteúdos relacionados a estudos atuais, como os Buracos Negros, Cosmologia, Astrofísica, Astrobiologia, dentre outros. Porém, conteúdos relacionados com a Astronomia Básica, como as estações do ano, eclipses, conceitos de dia, ano e outros aspectos, não são discutidos com mais profundidade. Para Langhi 
(2011), a ausência de estudos sobre estes conceitos reflete nas concepções alternativas, sendo necessárias ações para que estes conceitos sejam ensinados e compreendidos de forma eficiente.

A Astronomia Indígena, história da Astronomia e Astronomia Amadora também carecem de pesquisas que possam estimular as pessoas na valorização destes estudos. Os diferentes aspectos da Astronomia são essenciais para a compreensão humana sobre o conhecimento astronômico em várias culturas, épocas e locais. Além disso, outro aspecto relevante é o pequeno número de pesquisas que abordam a Astrologia e a Terra Plana, por exemplo. Discussões sobre a Ciência e as pseudociências são importantes para que as pessoas possam compreender o papel da Ciência para a humanidade e suas diferenças em relação às pseudociências. Ostermann e Cavalcanti (2011), a título de exemplo, abordam a necessidade de refletirmos sobre as complexas relações existentes na construção científica, nos diferentes métodos científicos e no contexto teórico e histórico no desenvolvimento de teorias científicas.

\subsection{Focos e subfocos temáticos}

Ao identificar os conteúdos de cada artigo, foi possível delinear tendências e problemas enfrentados pela educação não formal em Astronomia, como o grande número de pesquisas voltadas para a Astronomia, em geral, e o pequeno número de pesquisas sobre a importância dos astrônomos amadores, por exemplo. Em conjunto com a análise dos conteúdos, a distinção entre diferentes focos e subfocos temáticos também é importante, por apresentar possíveis tendências e fragilidades em alguns temas estudados pela educação não formal em Astronomia. $\mathrm{Na}$ Tabela 2 são apresentados os quatro focos temáticos e os subfocos.

Tabela 2 - Relação entre a quantidade de artigos e as instituições de origem

\begin{tabular}{ccc}
\hline Foco temático & Subfoco temático & $\begin{array}{c}\text { Total de } \\
\text { artigos }\end{array}$ \\
\hline \multirow{2}{*}{$\begin{array}{c}\text { Abordagem } \\
\text { Sociocultural }\end{array}$} & Equidade na Astronomia & 7 \\
\cline { 2 - 3 } & Astronomia Amadora & 7 \\
\hline Educação não & Astronomia Indígena & 6 \\
\hline formal & Astronomia e meio ambiente & 5 \\
\hline \multirow{2}{*}{$\begin{array}{c}\text { Espaços não } \\
\text { formais }\end{array}$} & A Educação formal e a não formal em Astronomia & 40 \\
\cline { 2 - 3 } & Tecnologia na educação não formal em Astronomia & 32 \\
\hline Pesquisas sobre & Atividades em espaços não formais & 41 \\
\cline { 2 - 3 } Astronomia & Pesquisas em espaços não formais & 14 \\
\cline { 2 - 3 } & Descrição de espaços não formais & 12 \\
\hline
\end{tabular}

Fonte: Elaborada pelos autores.

Os artigos que possuem como foco temático a Abordagem Sociocultural, apresentam 
pesquisas que se preocupam com o acesso ao conhecimento e trabalho científico por diferentes públicos. Além disso, fazem uma crítica quanto ao pequeno número de pesquisas relacionadas a temas que são, muitas vezes, deixados de lado pela comunidade científica e que desempenham um importante papel na compreensão da educação não formal em Astronomia. O primeiro subfoco, Equidade na Astronomia, apresenta artigos sobre o pequeno número de mulheres na pesquisa astronômica; políticas de acesso das minorias ao conhecimento astronômico e a necessidade de atividades de inclusão, para surdos e outras pessoas com necessidades especiais, em atividades não formais em Astronomia. As pesquisas sobre Astronomia Amadora reforçam a importância dos astrônomos amadores e suas atividades, como a divulgação da Astronomia e a captação de dados astronômicos em conjunto com astrônomos profissionais, por exemplo.

O subfoco Astronomia Indígena traz atividades indígenas relacionadas à Astronomia, como as queimadas feitas pelos índios ao observarem as constelações de determinada época, os problemas enfrentados por aldeias indígenas ao serem construídos telescópios em suas terras e o incentivo ao ensino de Astronomia Indígena nas escolas. A relação entre Astronomia e meio ambiente é investigada em pesquisas sobre a poluição luminosa, problemas ambientais relativos à construção de grandes telescópios e o lixo espacial. Os 25 artigos deste foco temático representam $11 \%$ do total, mostrando que estes temas carecem de pesquisas, mesmo que sejam necessários para o entendimento e promoção da educação não formal em Astronomia.

O segundo foco temático, Educação não formal, apresenta várias possibilidades para este tipo de educação, em Astronomia, através de dois subfocos temáticos. O primeiro subfoco, A educação formal e a não formal em Astronomia, apresenta diversas pesquisas que demonstram a importância desta proximidade entre os dois tipos de educação. Dentre as pesquisas, estão descrições de cursos e atividades não formais para alunos; experimentos; simulações; oficinas; olimpíadas do conhecimento; relações entre sistemas de ensino e a educação não formal em Astronomia, como os sistemas de ensino da Ucrânia e do Cazaquistão; atividades com materiais de baixo custo; observações astronômicas e visitas escolares a ambientes não formais; formação inicial e continuada de professores por meio de exposições astronômicas e cursos diversos e análise de concepções alternativas.

O segundo subfoco temático, Tecnologia na educação não formal em Astronomia, apresenta pesquisas sobre a importância da tecnologia neste tipo de educação. Dentre estas pesquisas, está o uso de softwares, ambientes virtuais, obtenção de dados astronômicos, uso de telescópios virtuais e robóticos, atividades virtuais em observatórios, cursos online abertos e massivos - MOOCs, plataformas virtuais, realidade virtual e aumentada, uso de podcasting, gráficos, Google Hearth, aplicativos e modelagem computacional. Ou seja, estas pesquisas 
demonstram a importância da tecnologia, por permitir o acesso ao conhecimento sobre Astronomia por muitas pessoas em vários ambientes e metodologias diversificadas.

O terceiro foco temático, Espaços não formais, demonstra a importância destes locais para a educação não formal em Astronomia e por complementarem o sistema formal de ensino através de diferentes atividades. Além disso, o público geral tem a oportunidade de aprender conceitos astronômicos nestes ambientes, o que pode incentivar as pessoas ao conhecimento de Astronomia e da Ciência, em geral. No subfoco Atividades em espaços não formais, são analisadas atividades em planetários, museus, centros de Ciências, observatórios, exposições itinerantes, clubes de Astronomia, dentre outros. São analisados cursos; atividades práticas; palestras; o trabalho de monitores e atividades do Ano Internacional da Astronomia, em 2009.

No subfoco Pesquisas em espaços não formais, foram feitas pesquisas por meio de questionários, entrevistas semiestruturadas e descrições de visitas a estes locais. Houve a análise de participantes sobre estes ambientes e a opinião dos mesmos a respeito de temas como a Astrologia, exploração espacial, criacionismo, Big Bang, religião e alienígenas. Também foram identificadas concepções alternativas de visitantes sobre eclipses e demais temas. No subfoco Descrição de espaços não formais, foram descritos grupos de Astronomia; laboratórios, como o Laboratório Nacional de Astrofísica (LNA), do Brasil; planetários; observatórios e museus.

No último foco temático são feitas reflexões sobre a importância de pesquisas científicas, por desenvolverem o conhecimento astronômico através de novas descobertas, além de revisões da produção acadêmica e análise de acontecimentos históricos. O subfoco Atividades científicas, consiste em um conjunto de pesquisas sobre a Astrofísica; o comportamento de cientistas; disciplinas de Astronomia; o caso Plutão; textos e descobertas científicas; relatos de experiências e demonstrações e pesquisas sobre Astrobiologia.

Também são apresentados projetos realizados por cientistas, como as missões espaciais; colaborações internacionais de divulgação e de agências espaciais, como a NASA e a IAU; política espacial do Japão e da África do Sul; aproximações de cientistas com o público geral, por meio de explicações sobre Astrobiologia; experiências realizadas nos ônibus espaciais e a Ciência Cidadã. No subfoco Revisão de literatura, são feitas revisões sobre teses, dissertações, artigos e eventos científicos, além de serem apresentadas pesquisas sobre interdisciplinaridade e a importância da educação formal e não formal em Astronomia.

No último subfoco, a história da Astronomia é apresentada através de relatos sobre a Astronomia mexicana; o pouso na Lua; os desafios da Astronomia nos últimos cem anos; história sobre meteoritos encontrados nos Estados Unidos; relatos de expedições e observações astronômicas relacionadas com os eclipses; história de comunidades científicas e de povos 
nórdicos; a história do telescópio Hubble; e a história da física espacial.

$\mathrm{Na}$ análise destes focos e subfocos é possível observar que a educação não formal em Astronomia possui um amplo campo de atuação. Desde relações com astrônomos profissionais e diferentes instituições até atividades com alunos, professores, indígenas, pessoas com necessidades especiais, astrônomos amadores e quaisquer outras pessoas que tenham interesse em aprender Astronomia. A quantidade de artigos que apresentam pesquisas científicas e aproximações com as instituições de ensino, demonstra que a educação não formal é importante por valorizar atividades diversificadas em ambientes diferentes da sala de aula. Do mesmo modo, a evolução da tecnologia permite a compreensão de fenômenos astronômicos através de vários recursos. Além disso, as várias atividades desenvolvidas em espaços não formais também refletem o papel destes ambientes na educação não formal, por aproximarem estudantes e o público, em geral, do conhecimento astronômico.

Embora este campo de atuação seja amplo, muitas pessoas e comunidades possuem pequeno espaço nas pesquisas. A equidade na Astronomia é pouco explorada nos estudos acadêmicos e a Astronomia Amadora e Indígena, embora muito importantes, também não são reconhecidas e investigadas como deveriam ser. Do mesmo modo, carecem de pesquisas a relação da Astronomia com o meio ambiente e a valorização da história da Astronomia.

\section{CONSIDERAÇÕES}

A análise dos artigos identificou várias tendências e problemas da educação não formal em Astronomia, a nível nacional e internacional. Como principais tendências, estão a ampliação do conhecimento astronômico e atividades de educação não formal em Astronomia em vários países. Embora os Estados Unidos detenham grande parte dos artigos e das revistas científicas analisadas, é possível observar esforços de autores de todo o mundo para produzir conhecimento científico nesta área.

As pesquisas realizadas no Brasil também se destacam, pois diversas instituições desenvolvem projetos e atividades relacionadas à educação não formal em Astronomia. Do mesmo modo, muitas revistas científicas se empenham para a divulgação e valorização da Ciência no Brasil. Embora tenha sido observado que estas pesquisas estão concentradas nas regiões Sudeste e Sul, existem incentivos, mesmo que alguns sejam tímidos, para que demais regiões ampliem suas pesquisas e o ensino de Astronomia por meio da educação não formal.

A diversidade de revistas científicas demonstra uma tendência mundial, na qual grande parte do conhecimento humano é acessível. Mesmo que uma elevada parcela das revistas esteja 
concentrada nos Estados Unidos, observa-se que existem revistas oriundas de parcerias internacionais, além de revistas de diversos países que divulgam pesquisas no nível mundial.

A respeito dos conteúdos, grande parte das pesquisas analisadas estudou a Astronomia, em geral, além de relatos de observações astronômicas e relações da educação formal com a educação não formal em Astronomia. Apesar desta tendência, a análise dos conteúdos constatou que muitos carecem de pesquisas. Dentre os problemas relacionados aos conteúdos, está a escassez de pesquisas sobre as relações da Astronomia e o meio ambiente e as concepções alternativas sobre o dia, o ano, as estações do ano e outros conteúdos da Astronomia Básica.

Os focos temáticos também apresentaram problemas sobre o pequeno número de artigos presentes em determinados temas. Ademais, complementando os problemas apresentados nos conteúdos, temas como a Astronomia Indígena; Astronomia Amadora; meio ambiente e equidade na Astronomia, como a inclusão, por exemplo, são os que carecem de pesquisas. Por outro lado, o uso da tecnologia e pesquisas sobre Astronomia, relações entre educação formal e não formal em Astronomia e os espaços não formais, apresentam resultados importantes.

Esta pesquisa contribui para a área de educação não formal em Astronomia através da análise de tendências, problemas e possíveis soluções desta temática. Como implicações, demais pesquisas e ações podem ser realizadas para que a Astronomia seja ensinada em todas as regiões do Brasil, assim como em outros paises que apresentaram poucas pesquisas nesta amostra. A participação de diversas instituições também pode ser incentivada, assim como a abordagem de temas e conteúdos presentes em poucos artigos. Quanto aos detalhes referentes aos temas, conteúdos e abordagens dos artigos podem auxiliar demais autores em suas pesquisas, originando novas ideias e ações.

\section{AGRADECIMENTOS}

Os autores agradecem o apoio concedido pela Coordenação de Aperfeiçoamento de Pessoal de Nível Superior (CAPES).

\section{REFERÊNCIAS}

ANDRÉ, M. E. D. A. Pesquisa em educação: buscando rigor e qualidade. Cadernos de Pesquisa, n. 113, p. 51-64, 2001. Disponível em: https://www.scielo.br/scielo.php?pid=S0100-15742001000200003\&script=sci_arttext. Acesso em: 15 jun. 2020.

AMARAL, P.; OLIVEIRA, C, E. Q. V. Astronomia nos livros didáticos de ciências: uma análise do PNLD 2008. Revista Latino-Americana de Educação em Astronomia, v. 12, n. 
12, p. 31-55, 2011. Disponível em:

http://www.relea.ufscar.br/index.php/relea/article/view/162. Acesso em: 15 jun. 2020.

Doi: https://doi.org/10.37156/RELEA/2011.12.031.

BARDIN, L. Análise de conteúdo. Lisboa: Edições 70, 2006.

BARBOSA, J. I. L.; VOELZKE, M. R. Questionário-diagnóstico sobre conceitos básicos de Astronomia por alunos do Ensino Médio Integrado. Revista de Ensino de Ciências e Matemática, v. 7, n. 2, p. 25-38, 2016. Disponível em:

http://revistapos.cruzeirodosul.edu.br/index.php/rencima/article/view/1146. Acesso em: 15 jun. 2020. Doi: https://doi.org/10.26843/rencima.v7i2.1146.

BELIZ, F. S. Construção de um jogo didático digital ligado à divulgação científica da astronomia. 2016. 112 f. Dissertação (Mestrado) - Universidade Estadual de Feira de Santana, Feira de Santana, 2016. Disponível em: http://tede2.uefs.br:8080/handle/tede/390. Acesso em: 15 jun. 2020.

BORGES, T. O. Aprendizagem em astronomia: o desenvolvimento de uma sequência didática a partir de reflexões sobre a organização de cenas presentes no ambiente do planetário móvel da Universidade Estadual de Mato Grosso do Sul. 2017. 81 f. Dissertação (Mestrado) - Universidade Estadual de Mato Grosso do Sul, Dourados, 2017.

BUENO, M. A.; OLIVEIRA, E. A. G., NOGUEIRA, E. M. E.; RODRIGUES, M. S. Astronomia Cultural: um levantamento bibliográfico dos saberes sobre o céu de culturas indígenas. Revista Amazônica de Ensino de Ciências, v. 11, n. 24, p. 27-40, 2019. Disponível em: http://periodicos.uea.edu.br/index.php/arete/article/view/1547. Acesso em: 15 jun. 2020.

BUSSI, B.; BRETONES, P. S. Educação em Astronomia nos Trabalhos dos ENPECs de 1997 a 2011. In: Encontro Nacional de Pesquisa em Educação em Ciências, Águas de Lindóia, SP, 2013. Disponível em: http://abrapecnet.org.br/atas_enpec/ixenpec/atas/resumos/R01441.pdf. Acesso em: 15 jun. 2020.

ESTEBAN, M. P. S. Pesquisa qualitativa em educação: fundamentos e tradições. Porto Alegre: AMGH, 2010.

LANGHI, R. Educação em Astronomia: da revisão bibliográfica sobre concepções alternativas à necessidade de uma ação nacional. Caderno Brasileiro de Ensino de Física, v. 28, n. 2, p. 373-399, 2011. Disponível em:

https://dialnet.unirioja.es/servlet/articulo?codigo=5165373. Acesso em: 15 jun. 2020. Doi: https://doi.org/10.5007/2175-7941.2011v28n2p373.

LANGHI, R.; NARDI, R. Educação em Astronomia: repensando a formação de professores. São Paulo: Escrituras editoras, 2012.

MARQUES, J. B. V.; FREITAS, D. Fatores de caracterização da educação não formal. Educação e Pesquisa, v. 43, n. 4, p. 1087-1110, 2017. Disponível em: https://www.scielo.br/scielo.php?pid=S1517-97022017000401087\&script=sci_arttext\&tlng =\%20pt. Acesso em: 15 jun. 2020. Doi: https://doi.org/10.1590/s1517-9702201701151678. 
MARQUES, J. B. V. Educação Não-Formal e Divulgação de Astronomia no Brasil: Atores e Dinâmica da área na Perspectiva da Complexidade. 2017, 306 f. Tese (doutorado) Universidade Federal de São Carlos, São Carlos. 2017. Disponível em:

http://www.btdea.ufscar.br/teses-e-dissertacoes/educacao-nao-formal-e-divulgacao-deastronomia-no-brasil-atores-e-dinamica-da-area-na-perspectiva-da-complexidade. Acesso em: 15 jun. 2020.

MEGID NETO, J. Educação ambiental como campo de conhecimento: a contribuição das pesquisas acadêmicas para sua consolidação no Brasil. Pesquisa em Educação Ambiental, v. 4, n. 2, p. 95-110, 2009. Disponível em:

http://www.periodicos.rc.biblioteca.unesp.br/index.php/pesquisa/article/view/6193. Acesso em: 15 jun. 2020. Doi: http://dx.doi.org/10.18675/2177-580X.vol4.n2.p95-110

MENEZES, L. P. G.; BATISTA, M. C. Concepções de mestrandos em ensino de Física sobre o Sistema Solar sob a perspectiva das leis de Kepler. REAMEC - Rede Amazônica de Educação em Ciências e Matemática, v. 8, n. 2, p. 352-373, 2020.

NOY, M. V.; JAMES, H.; BEDLEY, C. Reconceptualizing Learning: a review of the literature on informal learning. Pistacaway: ACT Fundation, 2016.

OSTERMANN, F.; CAVALCANTI, C. Epistemologia: implicações para o ensino de ciências. Porto Alegre: Evangraf; UFRGS, 2011.

SANTOS, H. L.; LUCAS, L. B.; SANZOVO, D. T.; PIMENTEL, R. G. O uso das tecnologias digitais para o ensino de Astronomia: uma revisão sistemática de literatura.

Research, Society and Development, v. 8, n. 4, p. 37, 2015.

YANO, V. T. B. Formação inicial e subjetividade docente no Centro de Ciências e Planetário do Pará. 2017. 117 f. Dissertação (Mestrado) - Universidade Federal do Pará, Belém, 2017. Disponível em:

https://www.researchgate.net/publication/328684452_Subjetividade_e_formacao_inicial_doc ente_no_Centro_de_Ciencias_e_Planetario_do_Para. Acesso em: 15 jun. 2020.

Submetido em: 15 de junho de 2020.

Aprovado em: 12 de julho de 2020. 